JWAM

9,2

Received 27 July 2017 Revised 27 August 2017 5 September 2017 Accepted 5 September 2017

\section{Impact through coaching: does the use of models limit connectedness in coaching?}

\author{
Rachel Veronica Robins \\ RVR Consulting, Wirral, UK
}

\begin{abstract}
Purpose - Models are currently used extensively in the delivery of coaching. These models are used to give structure and form by coaches. The purpose of this paper is to present an alternative viewpoint of the impact of the use of models in the coaching relationship.

Design/methodology/approach - The approach taken has been to reflect on recent conversations across professional networks. The cooperative curiosity and questioning of some of our professional assumptions explores using models in coaching to enhances our practice, rather than limiting it. The paper acts as an exploratory prompt to question our practice and the role of the coach in the client/coach relationship.

Findings - The paper suggests that models are used, to a greater extent by the more inexperienced coaches to support their early practice. It is suggested that with greater experience, there is less reliance and use of format and recognised models. The paper proposes the more experienced coach provides "freedom without models" creating an alternative type of environment.

Practical implications - The implications of this paper are that if the authors are to grow and develop the practice and profession, there is a need to continue to research what current practice is delivering and offering the clients. The authors need to question if the early career coaches have the skills to meet the needs of the clients who engage them.

Originality/value - Researching our practice intends to will spark new ideas that may enhance the coaching practice and deliver the requirements of clients looking for development in a volatile and challenging corporate business world.
\end{abstract}

Keywords Reflective practice, Coaching models, Coaching research

Paper type Viewpoint

This viewpoint paper explores the impact of reflective practice and work-based learning research from the coaching practitioner perspective. The term coach practitioner is applicable to many roles including, coach role model, expert coach, internal coach, performance coach, development/career coach and behavioural coach. Each of these different types of coach practitioner will fulfil the requirements of a different client group (Bachirova et al., 2014 in Cox et al., 2014). The importance for both coach and client is that there is an understanding and agreement on the type of coaching being provided. Not every client needs the same type of coaching, so it is important to establish requirements at an early stage. The experience and skill levels of these difference groups of practitioners may differ, but all need to be appropriate to the client group. Line managers, as a coach, are also practitioners; however, delivering coaching as a line manager also demands the highest qualities of managers and a willingness to adopt a fundamentally different approach to staff, as well as the skills in coaching (Whitmore, 2009). In the current periods of significant change and transition coaching as a tool or approach used by managers to help people learn and develop is growing in the workplace,

(C) Rachel Veronica Robins. Published in Journal of Work-Applied Management. Published by Emerald Publishing Limited. This article is published under the Creative Commons Attribution (CC BY 4.0) licence. Anyone may reproduce, distribute, translate and create derivative works of this article (for both commercial \& non-commercial purposes), subject to full attribution to the original publication and authors. The full terms of this licence may be seen at http://creativecommons.org/licences/by/4.0/ legalcode 
and this group has a significant contribution to make to research practice (Chartered Institute of Personnel and Development, 2015).

The European Mentoring and Coaching Council defines coaching as supporting "clients in achieving greater self-awareness, improved self-management skills and increased self-efficacy, so they develop their own goals and solutions appropriate to their context". If we then combine this with the International Coaching Federation's coaching definition as "partnering with clients in a thought-provoking and creative process that inspires them to maximize their personal and professional potential", we have a wider view. In this joint definition, the location of the coach has less importance than the impact of the relationship and the skill of the coach to support the client (European Mentoring and Coaching Council, 2015; International Coaching Federation, 2017).

This composite definition locates coaching in an individual developmental relationship where the coach's domain is future oriented - what does the client want, and then coaching the client to get there. Although, at times not divided by clear lines and boundaries, it is generally understood that coaching sits in the space between informal supportive conversations at one end and formal counselling at the other end. Informal conversations that are unstructured can be conducted by unqualified and inexperienced individuals. Formal counselling sessions are, in general, delivered by trained counsellors to diagnose and help clients with emotional and personality problems of the past. The coach operating in the space between informal conversations and counselling sessions is required to be qualified, have experience of coaching and fully understand the boundaries in which they operate (Bluckert, 2014).

This paper shares a viewpoint that qualified coaches, experienced and inexperienced, use coaching models differently. The viewpoint is based on lived experiences, practice wisdom and research evidence. The understanding and insight that comes from a practitioner viewpoint is important and legitimate to ensure that the development of practice is tracked over a period of time to improve practice and the client experience overall (Bachmann et al., 2017).

Whilst it is recognised that there is an abundance of literature on the use of executive coaching, skills and models used, this does not often give a clear picture of the activity that happens inside the coaching environment. Much of the research into coaching to date has been practitioner led into exploring how coaching works in organisations or situations (Cox et al., 2014) and not into different sectors or content of actual sessions. What is required is a better understanding of what aspects of coaching are the critical factors (Passmore and Fillery-Travis, 2011).

As a result of this lack of research, there have been a limited number of comprehensive studies of the component parts within the coaching process even though three elements of the coach-client relationship, duration of the process, and identification, of purpose and model of practice, are often identified from the literature (Fillery-Travis and Cox, 2014 in Cox et al., 2014). Fillery-Travis and Cox (2014 in Cox et al., 2014) suggest that the gaps are due to the multi-disciplinary nature of coaching and the lack of funding available for research. To increase research quantity and quality, it would require collaboration between researchers, sponsors, practitioners and professional bodies. This position is supported by Orenstein (2006) and Grant (2016) who, although writing seven years apart, arrive at the same conclusion that the lack of further rigorous research and academic debate are slowing the growth of the profession.

More recently, articles which discuss the nature of evidence-based practice and the virtue of practical wisdom have lately been enjoying a remarkable renaissance in management literature These papers aim to help further develop a more nuanced view of evidence-based approaches and the value of the practitioner evidence into coaching practice (Grant, 2016).

If coaching as a profession is to continue to develop, then the practitioner has a role in this development. The practitioner should be concerned as to how effectiveness is improved. 
JWAM

9,2

122

The benefit of any improvement will be to the profession and the industry equally (Fillery-Travis and Cox, 2014 in Cox et al., 2014). There continues to be calls for more forms of research which is relevant and generated through and in practice (Wall et al., 2016, 2017).

\section{Models as practice}

Models are invaluable to us in developing understanding. A model allows us to ensure we have travelled in the right direction and included all stages of a process. Maybe we feel we have even carried out our trade in accordance with a valid model. Coaching models can even help us to understand the coaching intervention from a system perspective and to understand the need for "structure" in the interaction between coach and client. There are implicit models in practice that shape what we do, and therefore, the outcomes we achieve (Wall, 2016a, b, c; Wall and Perrin, 2015; Holland et al., 1998).

If models help us to develop flexibility as coach practitioners, and they offer structure and an outline for both the coaching conversation and the overall coaching journey, then they serve us well. However, although models create a system within which the coach and client work, it is important that models are not experienced as either "prescriptive or rigid" (Wall, 2017; Wall and Jarvis, 2015; Wall and Rossetti, 2013). Sadly, many practitioners embarking on their careers believe that a coaching model is representative of what happens, or will happen, in the coaching conversation. They therefore do not move outside of this structure. It could be that here lies the danger. It can give the client an experience of being manoeuvred through a process, as a sheep would be driven though a sheep dip.

There is an alternative view of what practice should offer to a client. It could be that there are times in the coaching relationship when the use of models limits the connectedness of coach and client and the effectiveness of outcomes of the session. Models offer structure and a framework, but do we want structure in the coaching environment or do we want an open and honest conversation? We need to ask ourselves: do coaching sessions follow the coach's agenda or the clients? For me, a true connection with the client is the key to delivering a quality coaching session. This connection requires the coach at all times to be conscious of the clients agenda and personal outcomes and not allow their own agenda to enter the space, either consciously or unconsciously.

If the role of the coach is "a conscious, intelligent use of both support and challenging skills where the coach can shift dynamically depending on the circumstances and the environment" (Blakey and Day, 2012), then there could be a view that following a model through the session may limit the ability of the coach to follow the client. The suggestion is not for one minute that coaching models do not have a place in coaching. For the newly qualified coach, the structure and process that the models offer provide a format to follow and the safety of recognised stages to ensure that agreed outcomes are met (Holland et al., 1998). It could even be the case that using a model could keep the inexperienced coach consciously on the client's agenda. If the desire is to arrive at an agreed point inside a set time, then sticking to a rigid model may do the job. Practitioner experience shows that it takes practice of a considerable number of hours to become an effective coach and have the ability to shift dynamically depending on circumstances (Passmore, 2010a, b).

It is understandable that in the early days of practice, a coach would follow models which they have just learned rigidly (Whitmore, 2009). However, a cook who always follows recipes rigidly has consistent results, but does not innovate. Free from the recipe book, they can become truly creative - adding, and setting aside ingredients. That same person moves from a cook to a professional chef. They do not forget that there are recipes in the world but they create their own new recipes and leave the original recipe in the background of their knowledge. So a coach must develop their practice to grow professionally (Stober, 2014 in Cox et al., 2014). It takes time and effort to become skilled enough to use the appropriate strategies, tools and techniques to promote desirable and 
sustainable change for the benefit of the coachee and potentially for other stakeholders through coaching (Bachkirova et al., 2014 in Cox et al., 2014).

The current workplace is a very challenging environment. Clients present with an issue that even if they are comfortable to share, they do not always have the language to explain. Clients can present one issue, which in time develops very quickly into something emotionally embedded and may, even at this stage, not be recognised by the client themselves. Clients often require space for thoughts to form into words they are comfortable to say. We know that the confidential space, challenge and environment that coaching provides are highly treasured by the executives and they protect the thinking time it gives them (Robins, 2014). So providing space should be one of our aims. It could be said that not allowing space for the client to unfold and unpack their thoughts, and by moving the pace to the beat of a drum roll of a coaching model, follows the coach's path, not that of the client.

The coaching conversation needs to be about the client, not the coach. If coaching as described by Liz Merrick (Coach and Mentor - Twitter, 11 July 2017) "can be akin to an oxygen tank - a place where you can breathe, think and come out re-energised and re-focused", then it is wrong to restrict it to be limited by the confines of a ridged model. If the model is too prescriptive, it means the coach has their own agenda to fulfil, rather than attempting to understand the client's issues.

The best models can provide some useful structures for development if they are handled skillfully. At worst, they can be restricting and for more inexperienced individuals, a source of hiding place that can derail the coaching relationship. As we qualified, many of us learnt several models of coaching and these gave us the framework and context of the process of coaching (Wilson, 2011). However, as we grow in our experience, use our skills and develop our own practice, the models need to stay in the background and not be the cornerstone of our practice.

Unfortunately, all too often, evidence from across networks shows that the practice of a model is the start, the heart and the finish of a coaching session. This, for me, is the centre of the issue - newly qualified coaches and those who still require further development are developing their practice in the field for clients who have real issues. There is a danger that clients could be used as practice material for those developing their skills.

\section{An open space coaching approach offer}

The following is an example selected from recent practice which demonstrates the depth and breadth of issues from current working environments. These sessions were delivered without consciously applying existing models as it could be said that staying rigidly to a pre-defined format and set of set questions could have hindered the journey of the client. Rather, the coach unconsciously applies elements of models, drawn from experience, and used as appropriately during the sessions, just as the professional chef would pull together ingredients to form a new recipe. The approach was to give space for the client to speak freely unfolding their life in their current environment.

\section{Case study}

This client is an experienced Higher Education professional, with outstanding professional credibility, vast sector knowledge and national/international and regional reputation. However, they felt they were not coping with the working environment. They had sought coaching to assist in refocusing their energy to respond to their current stressful and highly demanding environment. Being in a senior role, this client felt that they were alone and unable to remove the blocks that were creating the stressful environment. The client felt that the relentless pressure was damaging their confidence and limiting their ability to respond to current issues. 
JWAM

9,2

124

The areas of development which they presented as their priorities for improvement were their personal resilience, increasing their own self-awareness and to regain their self-confidence in order to feel strong enough to change their current situation. At the first meeting, very little was shared about their current situation, and only brief details were given on current role and working practices.

These sessions did not follow a structured recognised model. They started in the early sessions with the client talking through what it had felt like being themselves in the workplace for the last month. This allowed the client to speak freely choosing what to include and what to leave out at this early stage. As the sessions progressed, it became clear that the real issue was a difficult relationship with a line manager and the workload allocation and distribution. Through an open space conversation, prompts and comments from the coach, the client heard herself voice the problem. She was, much to her surprise, being bullied by a line manager through the type of work she was being given.

By voicing incidents, meetings, corridor conversation and private one-to-one meetings, she realized she was the only member of the team who was voicing the opinion that current management behaviour was not appropriate. Over the early sessions, there was a great deal of personal questioning by the client as she did not think this could be bullying because of the roles of those concerned and the environment in with they worked. She also questioned her own position and challenged herself that as she was experienced in the workplace and was a strong individual, how could it be happening to her?

During the first three sessions, there was limited verbal intervention from the coach. However, there was a great deal of "connectedness" throughout every session. Asking questions of the client at this stage would run the risk of breaking the clients' emotional connection back with the workplace and them hearing the language themselves that had been used to them.

Quite often, when coaches start working with one issue or enquiry, they will find that there is something else underneath or behind it that will pop up. Responding to the current moment means that they will deal with or just be with whatever comes up in each moment and know that whatever arises and wherever individuals are in this moment is the perfect place for them right now. Everything that is happening is an opportunity for learning and movement.

The clients' development, gaining increased self-awareness, understanding blocking and procrastination behaviours, confidence building, visioning, action planning and defining future career developments and impacts were all areas which the client worked on with the coach over the following sessions.

Client feedback provided some six months after the last coaching session:

Thank you for the space you provided me to think. I feel you assisted me in removing the mental block that I had put in place as a self-protection mechanism. I now feel able to stand tall, think freely and enjoy life again! - Actually it is now more profound that this - the result has been that I am now able to reflect on the past experiences, acknowledge what I need, make good decisions and move forward with autonomy.

The clients' use of the "I" in their feedback shows how they have taken full responsibility for their own development. Coaching helped this client to get the best version of themself and unlock their potential. The increase in confidence during this time was significant, with improved self-awareness and a greater understanding of how their changed behaviour could lead to changed behaviour in others. This significant improvement led to a wider option of choices to change their life and take it in a different direction. The sessions did not follow a recognised model but that did not mean they were unstructured. The "open space" environment gave the opportunity for the client to unfold their situation and hear as they verbalised their own situation some of the areas that they wanted to change. These were then the areas that the following sessions concentrated on. 
The gift of connectedness

It seems rather obvious that a coach would have to listen to the client. However, there are many ways to listen to someone and on several different levels (Skiffington and Zeus, 2003). Sometimes listening to what people are avoiding saying or to what they are saying with their tone, body language or other non-verbal communications are every bit as important as what they do say (Passmore, 2010a, b). The greatest gift we can give to a client is to listen to them, completely and uninterrupted by thoughts of what is the next stage the coach needs the client to move to. For this to happen, there are two key elements - a connection between coach and client, and space for the client to think.

Therefore, there could be another interpretation of the coaching environment, one without models and set questions where it is as unstructured as possible. This open space environment gives space for the important and valuable elements of the relationship. It allows the coaching relationship to flow freely. It does not require the agreement of what outcome is required before it commences. In fact, this would not be possible as it is only the conversation itself that unfolds the desired outcome. Our intuition or sixth sense tells us things about our environment that the senses of sight, sound, smell, taste and touch cannot tell us. However, we need to develop it, strengthen and learn to listen to it. Quite often, we can get an "inner voice" and not listen to it because we do not trust our intuition or instincts. In giving the client space, people are taught that it is not so much about "being right" with their intuition, but the key is to have their senses sensitively tuned in to pick up signals, and then to speak directly from that place of intuition and then to respond to the current moment with whatever shows up.

When there is real connectedness between coach and client, they are linked at points in the conversation. They produce a close unit aiming for a single outcome - a better version of the client. At other points, only their touch points of understanding and the unfolding of events connect them. The approach to open space coaching practice comes very much from the belief that clients have the answers or they can find the answers if they are asked the right questions and given space. From the coach's point of view, nothing is wrong or broken and there is no need to "fix" the client. The coach is simply discovering, uncovering or polishing the individual that people already are (Bluckert, 2014). This approach is in line with that of the "Gestalt Coach" who strives to develop a quality interaction and collaborative partnership (Bluckert, 2014). This means that the coach and client relationship is focussed on getting the results that the client wants, not what the coach or anyone else thinks is best for the client. It is the coach's task to ensure that the clients are always steering towards fulfilment and balance, and are able to engage in the process of their lives.

We need to remain mindful of the evidence that it is the coaching relationship that matters more than any specific coaching tool, intervention or models used (Hall, 2013). Anything that enhances that relationship and the achievement of the coaching client's objectives is to be welcomed - but if the model becomes a diversion from the real work and purpose of the coaching, we should think again before using them as the mainstay of our practice. The people we surround ourselves with either raise or lower our standards, and this includes the coaches we select to work with. We all need people in our lives who raise our standards, remind us of our essential purpose and challenge us to become the best version of ourselves; surely, it is reasonable for the client to expect that from their coach also.

Models can help us to develop flexibility as coach practitioners (Dembkowski et al., 2006). They can offer structure and an outline for both the coaching session. However, although models create a system within which coach and client work, it is imperative that models are not experienced as either prescriptive or rigid or more importantly that you are following someone else's practice and not developing your own.
Impact

through

coaching

125 
JWAM

9,2

\section{Towards new spaces and possibilities}

We need to reflect and develop our practice to a level where we can create (or recreate) our own model of how we coach. This would allow us to examine our own practice and to understand what is important to us as individual coaches. Structuring our own practice to improve as a professional means, we develop as practitioners for the benefit of our clients (Bachkirova et al., 2014). As coaches, as we increase our own understanding of our own presence in the coaching space, we can develop more assurance and creativity of the interventions we use, including the "use of self" as defined in the Gestalt Coach approach (Bluckert, 2014).

A model represents a system with an implied process as part of it. It can be seen as a metaphor used to help us see and describe the journey through our coaching sessions. Models often contain stages, and these allow us to visualise the overall process. In other words, a model represents more than what you are looking at. If you can develop a personal approach that encompasses the coaching conversation and the entire coaching intervention, you will begin to work with considerably greater ease within your practice. As coaches, we need to have the confidence to build their own approach. This is your practice: shape it how you want it to develop. Include what is important. What is important is that you respond to the client in front of you not to a pre-prescribed model.

An "open space" approach builds on the work of Lane and Corrie (2006) and Bachkirova et al. (2014) in creating a personal model. It follows that what I feel are the important elements of coaching and follows my philosophy of space being the most important gift we can provide for clients. It encompasses my worldview of the value of listening to a client, allowing them to form in their own language what they need to understand to challenge their own thinking. In this alternative view, there are three key elements of a coaching relationship which are: increasing the clients awareness, increasing their trust in their own decision making and therefore increasing their future choices. These elements are delivered not through a model but through the connectedness of the coach in an open space environment. Space to think is valuable commodity a coach can offer as the quality of everything we do depends on the quality of the thinking we do first. The quality of our thinking depends on the way we treat each other while we are thinking (Nancy Kline, 2015).

\section{Moving forward}

Reflection on coaching practice continues to be an important element for the personal development of the practitioner. It is also important that the profession understands the development of newly qualified practitioners and follows them as they gain experience in a safe and supportive environment.

The author will continue to develop a personal approach of open space coaching through reflecting on how this approach meets the clients' agenda while increasing the professional ability of the practitioner. A further area for research will be to identify key skills that are required when coaching with an open space approach.

\section{References}

Bachmann, C., Habisch, A. and Dierksmeier, C. (2017), "Practical wisdom: management's no longer forgotten virtue", Journal of Business Ethics, Vol. 146, pp. 1-19.

Blakey, J. and Day, I. (2012), Challenging Coaching: Going beyond Traditional Coaching to Face the Facts, Nicholas Brealey Publishing, London.

Bluckert, P. (2014), “The Gestalt approach to coaching”, in Cox, J., Bachkirova, T. and Clutterbuck, D. (Eds), The Complete Handbook of Coaching, 2nd ed., Sage, London, pp. 26-30.

Chartered Institute of Personnel and Development (2015), "CIPD annual survey report: learning and development", CIPD, London. 
Cox, E., Bachkirova, T. and Clutterbuck, D. (2014), The Complete Handbook of Coaching, 2nd ed., Sage, London.

Dembkowski, S., Eldridge, F. and Hunter, I. (2006), Seven Steps of Effective Executive Coaching, Thorogood, London.

European Mentoring and Coaching Council (2015), "Competency framework glossary", available at: www.emccouncil.org (accessed 25 July 2017).

Grant, A.M. (2016), "What constitutes evidence-based coaching?: a two-by-two framework for distinguishing strong from weal evidence for coaching", International Journal of Evidence Based Coaching and Mentoring, Vol. 14 No. 1, p. 78.

Hall, L. (2013), Mindful Coaching: How Mindfulness can Transform Coaching Practice, Kogan Page, London.

Holland, D., Lachicotte, W. Jr, Skinner, D. and Chain, C. (1998), Identity and Agency in Cultural Worlds, Harvard University Press, Cambridge and Boston, MA.

International Coaching Federation (2017), "What is professional coaching?", available at: www. coachfederation.org (accessed 25 July 2017).

Kline, N. (2015), More Time to Think, Octopus Books, London.

Lane, D.A. and Corrie, S. (2006), The Modern Scientist-Practitioner: A Guide to Practice in Psychology, Routledge, London.

Orenstein, R.L. (2006), "Measuring executive coaching efficacy? The answer was right here all the time", Consulting Psychology Journal: Practice and Research, Vol. 58 No. 2, p. 106.

Passmore, J. (2010a), Excellence in Coaching: The Industry Guide, 2nd ed., Kogan Page, London.

Passmore, J. (2010b), Leadership Coaching: Working with Leaders to Develop Elite Performance, 2nd ed., Kogan Page, London.

Passmore, J. and Fillery-Travis, A. (2011), "A critical review of executive coaching research", A Decade of Progress and What's to Come. Coaching: An International Journey of Theory, Research and Practice, Vol. 4 No. 8, pp. 70-88.

Robins, R.V. (2014), "Executive coaching - a case study in local government".

Skiffington, S. and Zeus, P. (2003), Behavioural Coaching: How to Build Sustainable Personal and Organisational Strength, McGraw, North Ryde.

Wall, T. (2016a), “Author response: provocative education: from the Dalai Lama's Cat ${ }^{\circledR}$ to Dismal Land®”, Studies in Philosophy and Education, Vol. 35 No. 6, pp. 649-653.

Wall, T. (2016b), "Reviving the ubuntu spirit in landscapes of practice: evidence from deep within the forest”, Journal of Work-Applied Management, Vol. 8 No. 1, pp. 95-98.

Wall, T. (2016c), "Žižekian ideas in critical reflection: the tricks and traps of mobilising radical management insight", Journal of Work-Applied Management, Vol. 8 No. 1, pp. 5-16.

Wall, T. (2017), "Reciprocal pedagogies - flexible learning exemplar", in Devitt-Jones, S. (Ed.), Flexible Learning Practice Guide, HEA/QAA, York, pp. 21-22.

Wall, T. and Jarvis, M. (2015), Business Schools as Educational Provocateurs of Productivity via Interrelated Landscapes of Practice, Chartered Association of Business Schools, London.

Wall, T. and Perrin, D. (2015), Slavoj Žižek: A Žižekian Gaze at Education, Springer, London.

Wall, T. and Rossetti, L. (2013), Story Skills for Managers, CreateSpace, Charleston, CA.

Wall, T., Iordanou, I., Hawley, R. and Csigás, Z. (2016), Research Policy and Practice Provocations: Bridging the Gap: Towards Research that Sparks and Connects, The European Mentoring and Coaching Council, Brussels.

Wall, T., Jamieson, M., Csigás, Z. and Kiss, O. (2017), Research Policy and Practice Provocations: Coaching Evaluation in Diverse Landscapes of Practice - Towards Enriching Toolkits and Professional Judgement, The European Mentoring and Coaching Council, Brussels. 
JWAM

9,2

128

Wilson, C. (2011), Best Practice in Performance Coaching, Kogan Page, London.

Whitmore, J. (2009), Coaching for Performance GROWing People, Performance and Purpose, 4th ed., Nicholas Brealey, London.

\section{Further reading}

McLaughlin, M. and Cox, E. (2016), Leadership Coaching: Developing Braver Leaders, Routledge, New York, NY.

Stober, D.R. and Grant, A.M. (2006), Evidence Based Coaching Handbook, John Wiley and Sons, Hoboken, NJ.

\section{About the author}

Dr Rachel Veronica Robins, the Director of RVR Consulting, is a practicing Leadership and Behavioural Coach, Mentor and Mediator with a background as a Director of HR, Organisational Development and Improvement in the public sector. Her doctoral research area was in executive coaching in Local Government, and she continues to research into the personal development of professionals. She is a Fellow of CIPD and lectures on CIPD undergraduate and post-graduate programmes on leadership, development, strategic HRM, OD and HR professional practice. Dr Rachel Veronica Robins can be contacted at: rachel.robins980@btinternet.com

For instructions on how to order reprints of this article, please visit our website: 